\title{
Contingências históricas na trajetória comunicacional paulista: hipóteses de trabalho para uma agenda midiológica
}

\section{RESUMO}

Os processos comunicacionais na sociedade paulista foram determinados por contingências históricas, produzindo marcas indeléveis em sua fisionomia. Adotando a periodização usual nos estudos de História Política, o autor inventaria as singularidades evidenciadas pelas fontes secundárias da História Regional. Sua meta é construir hipóteses suscetíveis de inclusão na agenda investigativa da Midiologia Brasileira.

\section{PALAVRAS-CHAVE}

- midiologia brasileira

- indústrias midiáticas

- mídia paulista

\section{ABSTRACT}

Communication processes in the paulista society were established by historical circumstances, that generated deep marks on its face. By using the Political History regular division into periods, the author outlined a sample of singularities evidenced by secondary sources of the Regional History. His goal is to build hypothesis in order to be included in the agenda of Brazilian Media Studies.

\section{KEY WORDS}

- Brazilian media studies

- media industries

- paulista mass media

\section{José Marques de Melo UMESP}

A sociedade paulista apresenta, no seu itinerário comunicacional, singularidades que foram historicamente determinadas por contextos de natureza político-econômica ou geo-cultural.

$\mathrm{O}$ conceito de sociedade paulista não se limita à denotação geo-econômica, correspondendo ao contingente humano que vive dentro das fronteiras do Estado de São Paulo, unidade da República Federativa do Brasil situada na região Sudeste que concentra o maior parque industrial do país, além de produção agropecuária diversificada com elevado grau de produtividade. ${ }^{1}$ Esse conceito tem forte conotação sócio-política, em decorrência da hegemonia que São Paulo conquistou em todo o território nacional, exportando capitais e tecnologia, importando mãode-obra e valores culturais.

Trata-se de uma sociedade que "apresentou desde logo um acento preponderante: a mobilidade", ${ }^{2}$ responsável pela formação do seu tipo humano característico: o bandeirante, na visão de Manuel Diegues Junior. Ele foi gerado no ventre de uma economia colonial estigmatizada pela pobreza, que obrigou sua população masculina a desbravar terras longínquas em busca de riqueza. A pujança e a fartura só chegariam durante a transição entre os séculos XIX e $X X$, conjuntura marcada pela expansão da lavoura cafeeira como produto de exportação e pelo surto industrial que se agiganta no auge da imigração estrangeira.

Emergiu inevitavelmente uma civilização eivada de "dinamismo e contradições", cuja "aspiração à hegemonia nacional" se converte em "motivação básica do comportamento político dos paulistas". Essa "autoconfiança", segundo Love, "beirava a arrogância". ${ }^{3}$

Ao fazer um "exercício de memória", em busca da "identidade paulista", Carlos Guilherme Mota endossa a tese defendida por Milton Santos a propósito da "modernidade" precoce de São Paulo. "Isso, graças à importação, pelos imigrantes, de hábitos e aspirações, mas também pelo meio ambiente construído, próprio para uma expansão sustentada" ${ }^{4}$

Na base da sociedade paulista está o que Ernani da Silva Bruno classifica como "civilização de inspiração européia (a despeito de absorver valores de culturas estranhas à Europa)" ${ }^{5}$

Aroldo de Azevedo, ao esboçar o perfil étnico paulista, sugere que "essa população se caracteriza por sua heterogeneidade, descendendo de velhos e tradicionais troncos lusitanos, a que se acrescentam os que provêm da imigração iniciada na segunda 
metade do século XIX, a par de mestiços e negros, cuja presença e cuja formação remontam aos tempos coloniais". ${ }^{6}$

Com riqueza de detalhes, o geógrafo paulista exibe a complexidade da sociedade paulista, fruto de múltiplas convergências culturais. "Sem falar no stock indígena, hoje praticamente desaparecido, o Estado de São Paulo pode ser comparado a um microcosmo étnico. Brancos originários da Península Ibérica, da Bacia do Mediterrâneo e da Europa Central, cujos nomes de família relembram Portugal, Espanha, Itália, Líbano, Síria, Alemanha e outras áreas européias. Negros e mulatos, cujos ancestrais vieram de Angola e de Moçambique. Caboclos descendentes dos índios, que ainda no século XVIII, eram numerosos em terras paulistas, resquícios dos mamelucos do Brasil colonial. Amarelos de origem asiática, sobretudo vindos do Japão (...). Todos integrados na comunidade paulista, orgulhosos de a ela pertencer" ${ }^{\prime}$.

Durante o período da colonização lusitana, São Paulo caracterizou-se como espaço típico de germinação da identidade brasileira. Abrigando processos de interação simbólica que correspondiam às demandas das camadas rústicas da população, plasmou a mestiçagem étnica e fortaleceu a miscigenação cultural, fatores decisivos para a independência nacional.

O primeiro governo monárquico não conseguiu ocultar sua desconfiança, dificultando a implantação da imprensa nos Campos de Piratininga, como conseqüência da ousadia paulista no episódio da independência e de outros mal entendidos. Ao postergar o funcionamento da tipografia, reivindicada pelas autoridades provinciais, a Corte sonegou à elite regional o usufruto dos benefícios ensejados pelos seus produtos intelectuais.

Essa defasagem começa a declinar na fase republicana, cuja edificação contou, aliás, com expressiva participação de lideranças paulistas. Em meados do século XX, São Paulo protagonizaria feitos notáveis no âmbito comunicacional, assumindo a vanguarda das indústrias midiáticas do país (rádio, cinema, livro). Fomenta o pioneirismo no campo da Publicidade, das Relações Públicas, do Ensino de Jornalismo, da Imprensa Sindical e da Comunicação Empresarial, além de disseminar inovações como a Offset, a Televisão e a Internet, sem deixar de fortalecer a identidade brasileira, mesmo num cenário emoldurado pela globalização cultural.

É importante contextualizar alguns desses episódios para melhor compreensão do panorama histórico. ${ }^{8}$

\section{Período colonial}

No alvorecer da sociedade brasileira, São Paulo constituiu terreno fértil para o florescimento das redes contra-hegemônicas de circulação de informações e de idéias que Luiz Beltrão mais tarde identificaria como "sistema de folkcomunicação". 9

A "situação geográfica privilegiada" que ocupou no processo de colonização "por ser o centro do sistema hidrográfico da região", tornou a cidade de São Paulo "o centro do sistema de comunicação do planalto". Como bem descreveu Caio Prado Júnior, "o contato entre as diferentes regiões povoadas e colonizadas se faz necessariamente pela capital", onde desemboca a "antiga trilha dos índios, transformada em principal artéria da capitania".$^{10}$ Essa e outras trilhas foram responsáveis pela "projeção exterior" de São Paulo, determinando sua influência na "vida econômica" e na "paisagem" da região em que está localizada, o que "abrange não somente o Estado de que é capital, mas invade Estados vizinhos" ${ }^{11}$

\section{"depois de completado o processo da independência e coroado o primeiro Imperador do Brasil, o governo paulista passou a reivindicar a instalação de uma tipografia"}

Referindo-se às "veredas" utilizadas pelos "paulis-tas", para transpor "as matas espessas ou as montanhas aprumadas", dilatando as "fronteiras" do império luso-brasileiro, Sérgio Buarque de Holanda diz que elas constituíram uma espécie de "cartografia indígena" dotada de grande "poder de abstração, que não se concilia facilmente com certas generalizações (...) acerca da mentalidade primitiva". Se "entre os povos que ignoravam a palavra escrita, esses meios de comunicação" representavam "um admirável instrumento para triunfar sobre as condições mais poderosas e hostis", é natural que os bandeirantes recorressem freqüentemente à "comunicação indireta a fim de transmitir advertências e notícias, sempre que uma necessidade urgente se apresenta". Dentre as evidências anotadas pelos historiadores, encontra-se o "processo de sinalização por meio de fogueiras e rolos de fumaça, usado até hoje pelas nossas populações rurais" ${ }^{12}$

Ao mesmo sistema pertencem aquelas formas de expressão cultural engendradas pela catequese jesuítica no pátio do Colégio erigido no Planalto de Piratininga, embrião da atual metrópole paulistana. Elas foram basilares para fortalecer as redes alternativas de comunicação adotadas pelos missionários inacianos, na sua interlocução com os nativos. Seu principal motor foi a "língua geral", que as tribos indígenas já cultivavam em todo o litoral brasileiro. ${ }^{13}$

Devidamente codificada, ela se difundiu não apenas entre os "curumins" (índios catequizados), mas, sobretudo, entre os "mamelucos" (filhos mestiços de lusitanos e indígenas). 
Isolada da metrópole e praticamente ignorada pela burocracia estatal existente na sede do governo colonial, a sociedade paulista viu-se na contingência de recorrer a esse meio de comunicação como estratégia de sobrevivência. ${ }^{14}$ Empunhada pelos bandeirantes ${ }^{15}$ como arma para expandir as fronteiras nacionais, a "língua geral" teve papel preponderante na busca do ouro e dos diamantes. ${ }^{16}$ Seu uso generalizou-se de tal modo que só a partir de 1758, depois da expulsão dos jesuítas e no rastro da intervenção feita pelo Marquês de Pombal, a "língua portuguesa" seria adotada, no sentido de neutralizar a "tupização da vida cultural brasileira". ${ }^{17}$

A desolação e a decadência paulista agravaramse bem antes, quando ocorreu a redução do seu território, provocando despovoamento intensivo. ${ }^{18}$ A região desbravada pelos bandeirantes, onde havia fartura de minerais preciosos, foi amputada pela carta régia de 1720, passando a constituir capitania independente, sob o nome Minas Gerais. ${ }^{19}$

Nem mesmo as reformas pombalinas seriam suficientes para alterar o quadro de indigência cultural que caracterizava a fisionomia da sociedade colonial brasileira. São Paulo não foge ao perfil esboçado por José Honório Rodrigues: "Se no litoral havia ainda alguns rudimentos de cultura e instrução, a gente do interior regredia, ou, mesmo, se barbarizava, pois era incapaz de manter os contatos indispensáveis a uma civilização evoluída. (...) A vida econômica era atrofiada, sem liberdade nenhuma... (...) $\mathrm{O}$ mercado externo era fechado pela política do governo, e a disseminação da propriedade, as distâncias, as dificuldades de comunicação tornavam precário o mercado interno. (...) A barbarização da gente do interior, sem escola, sem livro e sem imprensa, continua seu processo negativo." 20

Massaud Moisés reconstitui apropriadamente o hiato cultural visível na fisionomia da sociedade paulista. "Depois de Anchieta, temos de aguardar muito tempo para que a vida cultural em São Paulo volte ao nível em que o missionário a deixou; razões de várias ordens histórico-econômica-social explicam que São Paulo, nos séculos seguintes, viesse a ocupar posição inferior à de outros centos culturais da Nação. Em tais momentos de crise, a atividade literária entrava em recesso ou degradava. É o que acontece praticamente ao longo dos séculos coloniais..." 21

O Brasil ingressa na era tipográfica logo após a chegada da Corte Portuguesa, quando o Regente D. João VI autoriza a criação da Imprensa Régia no Rio de Janeiro (1808) e a instalação de um prelo na Bahia (1811). No entanto, permanecendo vigente, o aparato repressivo inibe a expansão da imprensa em outras partes do território nacional. ${ }^{22}$ Logo que a censura foi abolida em Portugal, durante a liberalização empreendida pela Revolução do Porto (1820), os governos regionais de quatro províncias aproveitam o vácuo legal para instalar oficinas tipográficas (1821): Pernambuco, Maranhão, Pará e Minas Gerais. ${ }^{23}$

\section{Fase imperial}

São Paulo continuava ausente do mapa da imprensa, mesmo tendo sido palco do episódio que representou o divisor de águas da vida política nacional. ${ }^{24}$ Às margens do riacho Ipiranga, no dia 7 de setembro de 1822, D. Pedro lançou o brado separatista: "Independência ou Morte!", catalisando as aspirações coletivas que aplainaram o "caminho da emancipação política". ${ }^{25}$

Somente depois de completado o processo da independência e coroado o primeiro Imperador do Brasil, o governo paulista passou a reivindicar a instalação de uma tipografia. D. Pedro I acolhe favoravelmente a petição, mas a burocracia imperial faz vista grossa, protelando o desfecho. Durante os anos 1823-1824, quando os ânimos estavam acirrados na Corte do Rio de Janeiro, em meio às disputas constitucionais, o governador paulista apela inutilmente ao monarca brasileiro, sem conseguir demover seus resistentes acólitos, que certamente contabilizavam perdas e ganhos políticos de tal providência. Naquela conjuntura, os visionários como José Bonifácio Andrada, que fora artífice do "libelo paulista contra a pretensão recolonizadora das Cortes", permaneciam firmes na defesa de uma Constituição liberal. Quando o Imperador dissolve a Constituinte, outorgando a Carta de 1824, José Bonifácio já havia sido afastado do ministério, robustecendo as fileiras oposicionistas. A "crença abolicionista" e o endosso à tese da "justiça social", contrariando "o interesse dominante na quase totalidade da população branca", acabaram por afastar o Patriarca da Independência do centro de poder, condenando-o a um "prolongado exílio". ${ }^{26}$

Por esse e por outros supostos motivos, a população letrada de São Paulo esperaria até 1827 para ter acesso à tecnologia da imprensa.

O que explica o aparecimento tardio da imprensa paulista? O historiador Affonso de Freitas argumenta que essa lentidão é fruto das condições precárias existentes na sociedade local. "Como em geral soe acontecer com todos os inventos, a imprensa não antecipou, prevenindo-as, as necessidades sociais, aparecendo tão somente pela decorrência das mesmas". ${ }^{27}$ Ele destaca dois fatores responsáveis pela inibição da sociedade paulista ao desenvolvimento da imprensa: comércio pouco competitivo (dispensando anúncios para atrair compradores) e governo sem oposição ostensiva (despreocupado do cortejo popular em busca de apoio aos seus atos).

A imprensa paulista expandiu-se durante a primeira metade do século XIX. Não se trata, evidentemente, de "obra do acaso". Massaud Moisés em certo sentido a considera como "fruto da instalação da Faculdade de Direito", argumentando que o "sintoma expressivo desse estado de coisas é a proliferação de revistas paulistanas de alto nível intelectual, geralmente nascidas no ambiente da escola do Largo de São Francisco". ${ }^{28}$ 
No entanto, os jornais e revistas publicados durante os dois impérios tinham "vida efêmera". A maioria sequer durava uma "estação" e poucos conseguiram atravessar a barreira do "século".

Affonso de Freitas diz que, somente a partir de 1860, o "jornalismo foi se desenvolvendo progressivamente em correspondência com o desenvolvimento intelectual e material de S. Paulo." 29

\section{Etapa republicana}

Sem dúvida, as transformações operadas na economia paulista durante a Primeira República ${ }^{30}$ criaram melhores condições para a expansão do jornalismo impresso. Tanto assim que, em 1914, "todos os municípios paulistas, em número de 174 , dispõem de imprensa própria, sendo raros os que não contam com mais de um periódico de publicação regular", como anotou diligentemente Affonso de Freitas. Ele assinala também a ascensão dos jornais dos imigrantes estrangeiros, "tão acatados pelas massas ledoras quanto aqueles venerandos representantes da velha imprensa". ${ }^{31}$

São Paulo abandonava a retaguarda da imprensa nacional, conquistando a primazia do jornalismo brasileiro, o que inspira justo orgulho regional ao seu principal historiador. "Hoje a imprensa periódica de S. Paulo, indiscutivelmente a mais desenvolvida de todas as outras circunscrições brasileiras, apresenta todas as características do mais adiantado jornalismo e amplamente satisfaz as necessidades e as exigências da sociedade moderna em que o progresso da civilização transformou o velho e lendário domínio dos bandeirantes". ${ }^{32}$

Registro semelhante faria posteriormente o brazilianist Joseph Love. “Em 1912, São Paulo detinha o primeiro lugar nacional quanto ao número de periódicos publicados (...). Ainda detinha a liderança em 1930, quando ocupava o segundo lugar nacional no que se refere ao número de pessoas empregadas no jornalismo..." ${ }^{\prime 33}$

Espaço privilegiado de comunicação informativa ou utilitária, a imprensa se modernizava, refletindo naturalmente o dinamismo das transações comerciais e industriais, responsáveis pelo surgimento das atividades regulares de comunicação diversional e persuasiva.

São produtos da mesma conjuntura as primeiras agências de propaganda e o pioneiro serviço de relações públicas, embora se voltassem, num primeiro momento, para os segmentos da nossa elite.

"A comunicação de massa - observa Love - capaz de atingir os analfabetos", só se desenvolveria mais tarde, quando o cinema e o radio se beneficiam da expansão do nosso mercado interno. “Em 1937, São Paulo contava com mais de um quarto do total de 887 cinemas em todo o país." No mesmo ano, "28 das 63 estações de rádio brasileiras estavam localizadas em São Paulo. Dessas, 18 haviam sido instaladas fora da capital. Não é de surpreender, conse- qüentemente, que o maior número de aparelhos receptores estivesse concentrado em São Paulo, num total de 153.000 , ou $44 \%$ do total nacional." ${ }^{34}$

\section{Desenvolvimento capitalista}

O parque industrial de São Paulo foi construído no fim do século XIX e sedimentado nas primeiras décadas do século XX.

Heitor Ferreira Lima apresenta dados comparativos que atestam a mudança radical. Em 1900 funcionavam 165 estabelecimentos industriais, cifra que se agigantara em 1920 para 4.145 unidades fabris. Contudo, o principal contraste era de natureza qualitativa. "Antes, o que existia eram pequenas oficinas artesanais que mal davam para atender às necessidades locais e determinados produtos de consumo imediato". O autor completa o panorama, atualizando-o. "Dessa forma - em tempo relativamente curto - 50 anos apenas - construímos nosso parque manufatureiro e com ele pudemos ir suprindo o mercado interno em suas necessidades de artigo de consumo imediato." 35

A expansão do mercado consumidor de produtos nacionais, abastecido por diferentes indústrias, que passam a competir entre si (e muitas vezes com as mercadorias importadas) para merecer a preferência dos compradores potenciais, induz fabricantes e comerciantes a recorrer aos anúncios em jornais e revistas. Mas o que eles querem não é tão somente a compra do espaço nas páginas impressas, incluindo, sobretudo, a produção da mensagem persuasiva. Para atender a essa demanda surgem as agências de propaganda.

A primeira empresa do ramo foi a Publicidade Eclética, fundada em maio de 1914, pela dupla de jornalistas João Cataldi e Jocelyn Bennaton. Depois surgiram outras: Didier \& Vandagnoti, Harris, Pettinati e Edanée. As agências estrangeiras só entrariam no mercado paulista nas décadas de 20 e 30, quase sempre acompanhando clientes que montavam fábricas em território nacional. A precursora foi a Ayer \& Son, que veio servir a Ford. Logo depois, aportariam a Thompson e a McCann Erickson, disputando com as agências paulistas, as contas da General Electric, Westinghourse, Squibb etc. ${ }^{36}$

A pioneira Eclética inaugurou tanto a corretagem de anúncios, assumindo o papel do anunciante (fabricante ou comerciante) na relação com o veículo (jornal, revista, rádio etc.), quanto a identificação do mercado consumidor potencial. Explicando "como trabalha" sua agência, o sucessor dos fundadores, Julio Cosi enumerou as etapas de uma campanha. "Uma vez incumbida de realizar a propaganda de um determinado produto, nossa empresa, como qualquer outra agência de publicidade organizada, procura saber tudo o que nos poderá ser de grande utilidade na interpretação das qualidades daquele produto ao público. Antes de mais nada, fazemos um estudo completo da história do produto, desde 
sua fabricação: suas vantagens em face de outros produtos concorrentes, sua distribuição, sua publicidade no passado - se já é conhecido - etc. Também medimos o potencial aquisitivo dos clientes e procuramos descobrir as diversas peculiaridades do mercado para o produto em questão, passamos em seguida ao estudo dos veículos de propaganda mais adequados para o público que desejamos alcançar, examinando cuidadosamente suas características como elemento difundidor de cultura e propaganda, sua influência no meio onde é divulgado, seu alcance em qualidade e localidade, seus preços, e só então é que nos empenhamos no planejamento definitivo da campanha de propaganda." 37

A conjuntura mostrou-se favorável também ao florescimento das Relações Públicas. Atividade híbrida, situada na fronteira entre o Jornalismo e a Propaganda, as Relações Públicas haviam sido instituídas na América do Norte, no início do século XX, no momento em que o capitalismo selvagem vai sendo substituído por relações de produção mais equilibradas. Ao procurar harmonizar os benefícios do capital e do trabalho e ao patrocinar o diálogo entre o interesse público e os interesses privados, os novos profissionais da comunicação institucional ganham espaço na sociedade moderna. A primeira empresa a criar um serviço de Relações Públicas no Brasil foi a multinacional de origem canadense Light \& Power, em 1914, na tentativa de reduzir os conflitos que se avolumavam nos setores da energia elétrica e da água potável, cujo monopólio comercial lhe fora outorgado pelo governo brasileiro.

Vivíamos então o impacto da urbanização e da industrialização estimuladas pelos governos republicanos, chegando ao ápice dos fluxos migratórios procedentes da Europa e da Ásia. As massas urbanas se agitavam ciclicamente, instigadas pelas nascentes organizações sindicais, fazendo greves e desencadeando movimentos de protestos contra a carestia de vida ou a ineficácia dos concessionários de serviços públicos.

O pioneiro Departamento de Relações Públicas que a Light instalou na agência paulista, confiando seu comando a Eduardo Pinheiro Lobo, teve "ecos importantes, que ficaram sempre marcados na história da comunicação brasileira". Sua função precípua foi "harmonizar os interesses diversos da empresa e do público." ${ }^{38}$

Para bem entender o contexto em que prospera tal iniciativa, é conveniente lembrar que São Paulo estava imersa na onda sindicalista, cujo combustível era canalizado pelas páginas da imprensa operária. Trata-se de episódio emblemático através do qual transparece o acirramento dos conflitos entre as classes sociais no Brasil.

Em sua diligente avaliação desse período histórico, Maria Nazareth Ferreira, com autoridade de desbravadora do segmento de estudos da comunicação operária, afirma que a "politização das classes tra- balhadoras" é produto da "ativação da vida intelectual, com a fundação de jornais, clubes, circulação de livros e revistas científicas, debates sobre os problemas sociais e políticos, divulgação de informações internacionais..." ${ }^{39}$ São Paulo concentra, nessa ocasião, $42 \%$ dos títulos em língua portuguesa e 88,3 $\%$ dos títulos em idiomas estrangeiros da imprensa operária publicada no território nacional.

$\mathrm{Na}$ esteira dos acontecimentos que marcam o desenvolvimento capitalista na sociedade brasileira perfila o aparecimento do rádio. Se Pernambuco com a sua "rádio-clube" (1919) e o Rio de Janeiro com a sua "rádio-sociedade" (1923) disputam a primazia das atividades radiofônicas no Brasil, São Paulo vai ocupar lugar de realce no fortalecimento do "rádio publicitário".

\section{"poucos se davam conta de que, através do pórtico paulista, o Brasil ingressava definitivamente na era da comunicação de massa"}

Embora a Sociedade Rádio Educadora Paulista tenha sido criada em 1923, a emissora radiofônica por ela mantida entrou no ar, em caráter experimental, durante o ano seguinte, enfrentando sérias dificuldades financeiras. Com a captação de recursos doados por empresas privadas e pelo Estado de São Paulo, adquiriu um transmissor da Western Electric, que começou a ser operado somente em 1925.

A raiz da equação estava justamente no modelo radiofônico adotado inicialmente pelo Brasil. Inspirado no modelo europeu o rádio estava impedido de veicular propaganda comercial. Sua subsistência dependia das contribuições dos radio-ouvintes, das instituições beneméritas e do poder público. Estava destinado a ser veículo da elite, vocacionado para a divulgação científica e a difusão da cultura erudita, de acordo com a plataforma inicial concebida por Roquette Pinto.

No entanto, os visionários da radiodifusão paulista tinham intenções democráticas. Mário Ferraz Sampaio, observador participante dessa fase heróica da radiofonia paulista, oferece um testemunho importante. "Acompanhando o rádio desde o seu nascedouro em São Paulo, (...) posso adiantar que (...) os propósitos dos fundadores não eram propriamente elitistas: o rádio que imaginaram era aquele que se faria para a cultura e a educação, mas também para divertir o povo em suas horas de lazer". ${ }^{40}$

Esses ideais permanecem incubados até 1932, "data símbolo do rádio propagandístico", de acordo com a anotação feita pelo antropólogo João Baptista Borges, autor do pioneiro estudo sobre rádio e mobili- 
dade social no Brasil. Ele observa que a democratização do rádio paulista se dá como conseqüência do desenvolvimento econômico estimulado pela Segunda Guerra Mundial, produzindo a ampliação do nosso mercado interno e alterando a mentalidade antipublicitária dos nossos comerciantes e industriais.

Diante da concorrência esboçada por distintos fabricantes e marcas diferenciadas para os mesmos produtos, não havia outra saída senão persuadir os consumidores potenciais, através de anúncios. E naturalmente o rádio foi beneficiário imediato dos investimentos publicitários feitos pelos anunciantes nacionais e pelos fabricantes estrangeiros.

"Surgindo meio de surpresa, titubeando em seus primeiros dias de vida, (...) o rádio constituiu-se ao mesmo tempo em produto e em instrumento de expansão e consolidação do processo civilizatório urbano-industrial no país, através da difusão por toda a realidade brasileira de valores vinculados ao estilo de vida que aos poucos se esboçava entre nós". ${ }^{41}$

\section{Na vanguarda das inovações}

São Paulo passou a ser chamada de "locomotiva do Brasil", desde que assumiu a liderança do processo de industrialização, ampliando o mercado de trabalho para a mão-de-obra disponível no exército de reserva de outras regiões brasileiras e distribuindo bens e serviços para o mercado consumidor nacional.

A expressão metafórica ganhou intensidade na conjuntura posterior à Segunda Guerra Mundial, que coincide também com o período de redemocratização nacional e de crescimento da rede midiática, polarizando o complexo que depois seria rotulado como "indústria cultural".

É justamente nesse âmbito cultural-midiático que São Paulo passa a ocupar posição de vanguarda no panorama nacional, assimilando inovações procedentes do exterior, processando-as e transferindo-as para outras regiões, além de galvanizar avanços e conquistas cujos antecedentes situam-se em outros espaços da geografia brasileira.

Tal elenco começa pela educação superior dos profissionais da comunicação. Antiga reivindicação dos jornalistas, a criação de uma escola para formação específica arrastava-se desde 1918, quando a Associação Brasileira de Imprensa - ABI realiza no Rio de Janeiro o primeiro congresso nacional da categoria. Em 1935 Anisio Teixeira, fundador da Universidade do Distrito Federal, cria uma cátedra de jornalismo e confia sua direção a Costa Rego, ${ }^{42}$ mas o projeto logo foi abortado pelo Estado Novo que fecha a própria universidade. Enquanto a ABI insistia junto ao Ministério da Educação pleiteando a abertura de uma carreira no sistema federal, o empresário paulista Cásper Líbero antecipa-se à ação estatal, tomando a iniciativa de criar a primeira escola de jornalismo do país. A instituição começa a funcionar em 1947, agregada à Pontifícia Universidade Católica de São Paulo, tornando-se ponto de referência para entidades congêneres que iriam surgir em várias partes do nosso território, nas décadas posteriores.

Pouco depois, a capital paulista seria o palco de um evento planejado com pompa e circunstância. Em 1950, Assis Chateaubriand aqui inaugurou a primeira estação de televisão da América Latina.

"A festa foi transmitida dos estúdios instalados no morro do Sumaré, sendo captada em televisores estrategicamente situados no centro da cidade de São Paulo, de modo a suscitar a atenção popular". ${ }^{43}$

A cidade recebeu a inovação com absoluto ceticismo. Tanto assim que a imprensa ignorou solenemente o ato inaugural. Poucos se davam conta de que, através do pórtico paulista, o Brasil ingressava definitivamente na era da comunicação de massa. Embora Chateaubriand tenha entoado loas ao seu próprio feito, nas colunas que publicava em jornais de sua propriedade, talvez ele próprio tenha contribuído para que a inauguração passasse em brancas nuvens. Sérgio Matos dá uma chave para decifrar o mistério, lembrando que o timoneiro dos Diários e Emissoras Associados manteve os preparativos "às escondidas, pois ele queria inaugurar a televisão no Brasil antes do México e de Cuba", ${ }^{44}$ países que acabaram sendo beneficiários dessa inovação no mesmo ano.

Expandindo-se rapidamente por todo o país, o berço paulista da nossa televisão continuou fértil, propiciando formatos que conquistaram popularidade, como o teleteatro da TV Tupi, as telenovelas da TV Excelsior, os festivais da TV Record ou os programas educativos da TV Cultura. Na atualidade, São Paulo continua na dianteira das mutações tecnológicas, tendo protagonizado os testes para implantação da imagem de alta definição em laboratório montado na Universidade Mackenzie. ${ }^{45}$

Da mesma maneira que havia se adiantado, nos anos 60, assimilando o processo de impressão Ofsete, São Paulo teve lugar garantido na primeira fila da informatização da imprensa diária, no transcorrer da década de 80 .

Os louros cabem à empresa Folha de S. Paulo, cujo engajamento nas transformações dos padrões jornalísticos tem se mostrado antológico.

Mota \& Capelato anotaram com perspicácia o início dessa "revolução tecnológica", observando que em 1967 rodava-se no Brasil o primeiro jornal em ofsete - o diário "Cidade de Santos" - , teste que determinou a adoção do mesmo sistema, em 1968, pelo matutino "Folha de S. Paulo". ${ }^{46}$

Por sua vez, Ruth Vianna ${ }^{47}$ percorreu os bastidores da pugna para informatizar os jornais brasileiros, destacando dois momentos na trajetória da 
Folha de S. Paulo. Inicialmente, a informatização localiza-se na gráfica: em 1973, a fotocomposição é totalmente renovada. Finalmente, ela invade a redação: em 1983 as máquinas datilográficas são substituídas pelos terminais de computador.

Paralelamente a essas transformações de natureza tecnológica, São Paulo testemunhava e ao mesmo tempo nutria um novo filão comunicacional que iria crescer no interior das grandes empresas. Fazendo a mediação entre o capital e o trabalho, mas assumindo o prisma dos estrategistas empresariais, floresceria na Grande São Paulo um novo tipo de imprensa destinada a reduzir as tensões no interior das fábricas, dos bancos ou das construtoras.

O inventário histórico realizado por Gaudêncio Torquato, transparece nitidamente a liderança paulista nesse campo. O primeiro jornal empresarial foi aqui editado em 1925 pela Light. Outras publicações que marcaram a fisionomia da área também são paulistas: o boletim "Nossa Estrada" (1929), o jornal "Ferrovia" (1938), as revistas "Vida na GMB" (1949 e “Família VW" (1963). Desde 1967, São Paulo sedia a entidade que aglutina todos os projetos brasileiros dessa natureza - a Associação Brasileira de Jornalismo e Comunicação Empresarial - ABERJE. ${ }^{48}$

A internet chega ao Brasil em 1988, contando com a participação decisiva da Fundação de Amparo à Pesquisa do Estado de São Paulo - FAPESP. E já em 1994, o jornal “O Estado de S. Paulo" utilizava a rede mundial de computadores para fazer a cobertura da Copa Mundial de Futebol. No entanto, o passo decisivo para a nossa presença no espaço digital se dá em 1996, com a fundação da UOL - Universo On Line, através de uma parceria entre as empresas "Folha de S. Paulo" e "Editora Abril",49 empreendimento que assumiria a dianteira dos produtores de conteúdo em língua portuguesa.

"A grande contribuição dessa nova empreitada, chamada UOL, além de agregar sob um mesmo guarda-chuva conteúdos de dois gigantes da comunicação analógica, foi ser responsável pelos primeiros experimentos com vídeos na internet brasileira." 50

\section{Conclusão}

O conjunto de particularidades existentes em diferentes períodos da História da Comunicação Paulista, aqui resgatadas sob a forma de hipóteses de trabalho, representa um convite aos jovens pesquisadores da midiologia brasileira para a realização de estudos em fontes primárias. Somente através de análises comparativas será possível demonstrar a persistência desses indicadores ou evidenciar as mutações experimentadas no tempo e no espaço.

Não obstante este exercício retrospectivo tenha permitido visualizar algumas tendências constantes, elas não oferecem segurança para ensejar generalizações. Devem ser tomadas em sua exata dimen- são, ou seja, como pistas analíticas que, em certos momentos, suscitam apetite cognitivo, demandando observação duradoura e interpretação acurada.

Tantas singularidades transformam São Paulo num espaço de convergência, ou melhor, num pólo midiático, cujo conteúdo é o próprio vanguardismo lo$\mathrm{cal} /$ regional. Atraindo contingentes de visitantes, durante todo o ano, a cidade se torna vitrine da produção estadual, exibindo mercadorias, imagens e símbolos que procedem de toda a geografia paulista, percorrendo "trilhas" e "veredas" que muitas vezes ganham notoriedade mundial.

"São Paulo, locomotiva do Brasil". "São Paulo, pátria dos bandeirantes". "São Paulo, terra de oportunidades".

As metáforas tornam-se realidade palpável neste início de milênio, como bem definiu Jomar Moraes.

"Na tentativa de explicar a grandiosidade de São Paulo, como centro de gravidade da economia nacional, muitos rótulos já foram usados. São Paulo continua a ser tudo isso, mas (...) não há mais dúvida de que a cidade (...) tornou-se também a capital dos serviços e da tecnologia, símbolos maiores da economia globalizada. Que cidade brasileira, senão ela, poderia acolher, num único ano, 15 milhões de pessoas em torno de feiras e exposições e movimentar 2,5 bilhões de dólares somente com turismo de negócios?" 51 -aAmEcos

\section{NOTAS}

1. LAROUSSE CULTURAL - Brasil A/Z, São Paulo, Editora Universo, 1988, p. 747.

2. DIEGUES JUNIOR, Manuel - Regiões Culturais do Brasil, Rio de Janeiro, INEP, 1960, p. 235-236.

3. LOVE, Joseph - A locomotiva, Rio de Janeiro, Paz e Terra, 1982, p. 140-141.

4. MOTA, Carlos Guilherme - São Paulo: exercício de memória, Estudos Avançados 17 (48), 2003, p. 241.

5. BRUNO, Ernani da Silva, org. - São Paulo, terra e povo, Porto Alegre, Editora Globo, 1967, p. 1.

6. Azevedo, Aroldo - A rede urbana paulista, In: BRUNO, Ernani da Silva, org. - São Paulo, terra e povo, Porto Alegre, Editora Globo, 1967, p. 65.

7. Azevedo, Aroldo - A rede urbana paulista, In: BRUNO, Ernani da Silva, org. - São Paulo, terra e povo, Porto Alegre, Editora Globo, 1967, p. 65. 
8. Fonte complementar para esse exercício cognitivo é sem dúvida o livro coletivo São Paulo na Idade Mídia - organizadores: José Marques de Melo e Antonio Adami - São Paulo, Arte \& Ciência Editora, 2004.

9. BELTRÃO, Luiz - Folkcomunicação, Porto Alegre, Editora da PUCRS, 2001.

10. PRADO JR., Caio - A cidade de São Paulo: geografia e história, 13 ${ }^{\text {a }}$. Ed., São Paulo, Brasiliense, p. 27-28.

11. PRADO JR., Caio - A cidade de São Paulo: geografia e história, $13^{\mathrm{a}}$. Ed., São Paulo, Brasiliense, p. 80-81.

12. HOLANDA, Sergio Buarque de - Caminhos e Fronteiras, Rio de Janeiro, José Olympio, 1957, p. 22-23.

13. Segundo Capistrano de Abreu, a língua geral era "assim chamada por sua área de distribuição". Predominava "próximo de beira mar", sendo produto de três migrações: a dos carijós ou guaranis, a dos tupiniquins e a dos tupinambás. "O centro de irradiação das três migrações deve procurarse entre o rio Paraná e o Paraguai". ABREU, J. Capistrano - Capítulos de História Colonial (1500-1800), 5 ${ }^{\text {a }}$ Ed. Brasília, Editora da UnB, 1963, p. 40.

14. Em seu "Esboço da História Econômica de São Paulo", Alice Canabrava explica que o fracasso da agroindústria açucareira em São Vicente, no século XVI, empurrou a sociedade paulista para uma "economia de subsistência" que se projeta durante os séculos XVII e XVIII. Para ter acesso aos "objetos manufaturados que não estavam em condições de produzir", os paulistas adotaram um "gênero de vida novo, cujo escopo essencial foi a captura do índio", convertido em "mercadoria de troca". BRUNO, Ernani da Silva - São Paulo: terra e povo, Porto Alegre, Editora Globo, 1967, p. 22-23.

15. Alice Canabrava assim define o bandeirante: "um novo tipo social...(...) caracterizado como resultado de uma projeção de forças econômicas e sociais da capitania vicentina e que historicamente se perpetuou até nossos dias como um símbolo de audácia, de pioneirismo, de empreendimento e de vigor físico e mental". BRUNO, Ernani da Silva - São Paulo: terra e povo, Porto Alegre, Editora Globo, 1967, p. 23-24.

16. HOLANDA, Sergio Buarque de, org. - História Geral da Civilização Brasileira, tomo I - A Época Colonial, vol. 1 - Livro V, Cap. II - “As bandeiras na expansão geográfica do Brasil", São Paulo, Difusão Européia do Livro, 1968, p. 273-281

17. RODRIGUES, José Honório - Aspirações nacionais, São Paulo, Fulgor, 1963, p. 45

18. Tal episódio foi assim resumido por Caio Prado Junior: "A descoberta do ouro em Minas Gerais, pouco depois seguida pela de Goiás e Mato Grosso, representa a meta final do esforço tenaz dos paulistas durante quase dois séculos, votado ao reconhecimento de todo o território que havia de constituir o Brasil de hoje, e à procura de metais preciosos. São Paulo encerra sua obra e entra numa fase de prolongada estagnação. Não só interrompe sua ação colonizadora, mas se despovoa. Seus habitantes (...) vão se estabelecer em novas capitanias criadas à sua custa." PRADO JR., Caio - A cidade de São Paulo: geografia e história, 13a. Ed., São Paulo, Brasiliense, p. 32

19. HOLANDA, Sergio Buarque, org. - História Geral da Civilização Brasileira, tomo I - A Época Colonial, vol. 2 - "Cronologia sumária", São Paulo, Difusão Européia do Livro, 1968, p. 460

20. RODRIGUES, José Honório - Aspirações nacionais, São Paulo, Fulgor, 1963, p. 44

21. BRUNO, Ernani da Silva - São Paulo: terra e povo, cap. 9 (A literatura em São Paulo - Massaud Moisés). Porto Alegre, Editora Globo, 1967, p. 193.

22. A alforria da imprensa ocorre no dia 13 de maio de 1808. Mas, segundo Costella, "mal se instalava a imprensa e já em 24 de junho de 1808 - um mês depois, portanto - exteriorizavam-se as inevitáveis preocupações em torno da censura. (...) Essa preocupação com a censura s antecipou até mesmo às de ordem administrativa, pois normas nesse sentido só foram baixadas pelo /aviso de 26 de junho de 1808. Logo depois, (...) D. João, por decreto de 27 de setembro, nomeou censores régios." COSTELLA, Antonio - O controle da informação no Brasil, Petrópolis, Vozes, 1970, p. 20-21.

23. MARQUES DE MELO, José - História Social da Imprensa, Porto Alegre, Editora PUCRS, 2003, p. 95.

24. Segundo Boris Fausto, a estratégia de "fazer de São Paulo o cenário da ruptura final" foi idealizada pelo ministro paulista José Bonifácio de Andrada, que patrocinava a tese da Monarquia Constitucional para o Brasil, opondo-se à convocação de uma Assembléia Constituinte. Reconhe- 
cido como o Patriarca da Independência, trata-se de figura controversa. "Politicamente, era um liberal conservador", embora defendesse "idéias progressistas no campo social", como a abolição da escravatura, a reforma agrária e o estímulo à imigração estrangeira. FAUSTO, Boris - História do Brasil, 2a . Ed., São Paulo, EDUSP, 1995, p. 129-134 e 147-152.

25. HOLANDA, Sergio Buarque, org. - História Geral da Civilização Brasileira, tomo I - O Brasil Monárquico, vol. 1, Livro V - "A caminho da emancipação política”, São Paulo, Difusão Européia do Livro, 1968, p. 355-417.

26. HOLANDA, Sergio Buarque, org. - História Geral da Civilização Brasileira, tomo I I - O Brasil Monárquico, vol. 1, Livro 2 - "O movimento da independência", São Paulo, Difusão Européia do Livro, 1968, p. 166-167.

27. FREITAS, Affonso de - A imprensa periódica de São Paulo, Revista do Instituto Histórico e Geográfico de São Paulo, vol. XIX, São Paulo, 1915, p. 523.

28. MOISÉS, Massaud - A literatura em São Paulo, In: BRUNO, Ernani da Silva - São Paulo: terra e povo, Porto Alegre, Editora Globo, 1967, p.197.

29. FREITAS, Affonso de - A imprensa periódica de São Paulo, Revista do Instituto Histórico e Geográfico de São Paulo, vol. XIX, São Paulo, 1915, p. 537.

30. Sintoma dessa pujança da economia paulista no fim do século XIX é certamente a hegemonia conquistada no cenário político brasileiro. “Nos primeiros anos da República, São Paulo liderava indiscutivelmente a vida política nacional, fato claramente evidenciado pelo controle que a máquina política estadual exerceu sobre a presidência durante 12 anos, a partir de 1894. LOVE, Joseph - A locomotiva: São Paulo na Federação Brasileira, 1889-1937, Rio de Janeiro, Paz e Terra, 1982, p. 149.

31. FREITAS, Affonso de - A imprensa periódica de São Paulo, Revista do Instituto Histórico e Geográfico de São Paulo, vol. XIX, São Paulo, 1915, p. 537-538.

32. FREITAS, Affonso de - A imprensa periódica de São Paulo, Revista do Instituto Histórico e Geográfico de São Paulo, vol. XIX, São Paulo, 1915, p. 541

33. LOVE, Joseph - A locomotiva, Rio, Paz e Terra, 1982, p. 130
34. LOVE, Joseph - A locomotiva, Rio, Paz e Terra, 1982, p. 131

35. LIMA, Heitor Ferreira - O parque industrial em São Paulo, In: BRUNO, Ernani da Silva - São Paulo: terra e povo, Porto Alegre, Editora Globo, 1967, p.113-118.

36. RABELO, Genival - Os tempos heróicos da propaganda, Rio de Janeio, PN, 1956, p. 81-94.

37. RABELO, Genival - Os tempos heróicos da propaganda, Rio de Janeio, PN, 1956, p. 92-93

38. TORRES, Mirtes Vitoriano - Gênese do Pensamento Brasileiro nas Relações Públicas (tese de doutorado), São Bernardo do Campo, Universidade Metodista de São Paulo, 2005.

39. FERREIRA, Maria Nazareth - A imprensa operária no Brasil, 1880-1820, Petrópolis, Vozes, 1978, p. 48.

40. SAMPAIO, Mario Ferrraz - História do Rádio e da Televisão no Brasil e no mundo (memórias de um pioneiro), 2a . Ed., Campos, Ed. Fenorte, 2004, p. 119.

41. PEREIRA, João Baptista Borges - Cor, profissão e mobilidade - o negro e o rádio em São Paulo, São Paulo, Pioneira, 1967, p. 45-62.

42. MARQUES DE MELO, José - História do Pensamento Comunicacional, São Paulo, Paulus, 2003, 293-316.

43. MARQUES DE MELO, José - Imprensa Brasileira: personagens que fizeram História, vol. I, São Paulo, IMESP, 2005, p. 131.

44. MATTOS, Sérgio - História da Televisão Brasileira, 2a . Ed., Petrópolis, Vozes, 2002, p. 171.

45. MATTOS, Sérgio - História da Televisão Brasileira, 2a . Ed., Petrópolis, Vozes, 2002, p.154.

46. p. 200-201.

47. VIANNA,Ruth - A informatização da imprensa brasileira, São Paulo, Loyola, 1992, p. 30-32.

48. TORQUATO, Gaudêncio - Jornalismo Empresarial, São Paulo, Summus, 1984, p. 27-28.

49. LIMA, Walter - Webmídia: capítulo paulista da mídia emergente, In: MARQUES DE MELO \& ADAMI, orgs. - São Paulo na Idade Mídia, São Paulo, Arte \& Ciência, 2004, p. 339-348. 
50. LIMA, Walter - Webmídia: capítulo paulista da mídia emergente, In: MARQUES DE MELO \& ADAMI, orgs. - São Paulo na Idade Mídia, São Paulo, Arte \& Ciência, 2004, p. 345.

51. MORAES, Jomar - A capital da nova economia, http://www.planetajota.jor.br/sampa.htm, Ano V, n. 292, 2/5/2000

\section{REFERÊNCIAS}

ABREU, J. Capistrano. Capítulos de História Colonial (1500-1800). $5^{\text {a }}$ ed. Brasília, Editora da UnB, 1963.

BELTRÃO, Luiz. Folkcomunicação. Porto Alegre, Editora da PUCRS, 2001.

DIEGUES JUNIOR, Manuel. Regiões Culturais do Brasil. Rio de Janeiro, INEP, 1960.

FAUSTO, Boris. História do Brasil. $2^{\mathrm{a}}$ ed. São Paulo, EDUSP, 1995.

FERREIRA, Maria Nazareth. A imprensa operária no Brasil, 1880-1820. Petrópolis, Vozes, 1978.

FREITAS, Affonso de. A imprensa periódica de São Paulo,. Revista do Instituto Histórico e Geográfico de São Paulo, vol. XIX. São Paulo, 1915.

HOLANDA, Sergio Buarque de. Caminhos e Fronteiras. Rio de Janeiro, José Olympio, 1957.

HOLANDA, Sergio Buarque de (org.) História Geral da Civilização Brasileira. São Paulo, Difusão Européia do Livro, 1968.

LOVE, Joseph. A locomotiva. Rio de Janeiro, Paz e Terra, 1982.

MARQUES DE MELO, José. História do Pensamento Comunicacional. São Paulo, Paulus, 2003.

- História Social da Imprensa. Porto Alegre, Editora PUCRS, 2003.

_- Imprensa Brasileira: personagens que fizeram História, vol. I. São Paulo, IMESP, 2005.

MARQUES DE MELO \& ADAMI, orgs. São Paulo na Idade Mídia. São Paulo, Arte \& Ciência.

MATTOS, Sérgio. História da Televisão Brasileira. $2^{\mathrm{a}}$ ed. Petrópolis, Vozes, 2002.
MOTA, Carlos Guilherme. São Paulo: exercício de memória, Estudos Avançados 17 (48). São Paulo, Universidade de São Paulo, 2003, p. 241-263.

PEREIRA, João Baptista Borges. Cor, profissão e mobilidade - o negro e o rádio em São Paulo. São Paulo, Pioneira, 1967.

PRADO JR., Caio. A cidade de São Paulo: geografia e história, $13^{a}$ ed. São Paulo, Brasiliense, p. 8081.

RABELO, Genival. Os tempos heróicos da propaganda. Rio de Janeiro, PN, 1956.

RODRIGUES, José Honório. Aspirações nacionais. São Paulo, Fulgor, 1963.

SAMPAIO, Mario Ferrraz. História do Rádio e da Televisão no Brasil e no mundo (memórias de um pioneiro), $2^{\mathrm{a}}$ ed. Campos, Fenorte, 2004.

TORRES, Mirtes Vitoriano. Gênese do Pensamento Brasileiro nas Relaçães Públicas (tese de doutorado). São Bernardo do Campo, Universidade Metodista de São Paulo.

VIANNA, Ruth. A informatização da imprensa brasileira. São Paulo, Loyola, 1992.

TORQUATO, Gaudêncio. Jornalismo Empresarial. São Paulo, Summus, 1984, p. 27-28. 